\title{
Efficacy of Hyaluronic Acid Gel as an Adjunct to Non-Surgical Periodontal Treatment in Smokers with Periodontitis: A Retrospective Case Control Study
}

\author{
Hafize Ozturk Ozener (D), Omer Birkan Agrali (D), Hatice Selin Yildirim (iD \\ Marmara University, Faculty of Dentistry, Department of Periodontology, Istanbul, Turkey.
}

Correspondence Author: Hafize Ozturk Ozener

E-mail: hafize.ozturk@marmara.edu.tr

Received: 26.03.2020 Accepted: 20.05.2020

\begin{abstract}
Objective: To investigate the clinical effectiveness of adjunctive hyaluronic acid (HA) application to non-surgical periodontal treatment (NSPT) on periodontal parameters and gingival crevicular fluid (GCF) volume in smoking patients with stage III and grade C periodontitis.

Methods: Records of patients who underwent previously NSPT with or without HA gel application were reviewed. The clinical examinations and radiographs of patients, which were collected, are used as data. At baseline, 1 and 3 months, periodontal parameters such as plaque index (PI), gingival index (GI), bleeding on probing (BOP), probing depth (PD) and clinical attachment level (CAL), and GCF volume were assessed.

Results: Total 20 patients (male/female: 15/5) were included in the study who met the eligibility criteria. For 10 of these patients only NSPT was performed (Control group), the other 10 patients received NSPT with HA gel application (Test group). Intra-group differences in both groups were significant in periodontal parameters: PI (both, $p<0.001$ ), GI (both, $p<0.001$ ), BOP (both, $p<0.001$ ), PD (both, $p<0.05)$ and CAL (both, $p<0.05$ ); and in GCF volume (both, $p<0.05$ ). No statistically significant differences were determined between the treatment groups at any assessment time periods in any outcomes (all, $p>0.05$ ) nor in the changes $(\Delta)$ with time (all, $p>0.05$ ).

Conclusion: Compared to NSPT alone, the application of HA as adjunct to NSPT did not have any additional clinical effectiveness in smokers having periodontitis.

Keywords: Gingival crevicular fluid, hyaluronic acid, periodontitis, root planing
\end{abstract}

\section{INTRODUCTION}

Hyaluronic acid (HA) is a naturally occurring glycosaminoglycan with a high molecular weight, which is existing in various body fluids, including saliva, gingival crevicular fluid (GCF), serum and synovial fluid. HA plays complex roles in maintaining homeostasis in the body and regulating various biological processes (1). It is also a major element of the extracellular matrix of non-mineralized and mineralized tissues, such as the skin, the joints, the eyes, and the periodontium (24). HA shows bacteriostatic (5), anti-inflammatory (6), fungastatic (7), osteoinductive $(8,9)$, anti-oedematous (10) and pro-angiogenetic (11). To date, HA-based biomaterials and exogenous HA have shown success in an extraordinarily broad range of biomedical usage for the treatment of wound healing and inflammation in ophthalmology, dermatology and orthopedics (10).

Hyaluronan synthase enzymes in cells in periodontal tissues (fibroblasts and keratinocytes in the gingiva and periodontal ligament, cementoblasts in the cementum and osteoblasts in the alveolarbone) synthesize hyaluronan in periodontal tissues (12). It exists a higher amount in the periodontal ligament and gingiva compared to the cementum and alveolar bone (10, 13-18). HA is a critical component in maintaining of healthy periodontal tissue, the most abundant glycosaminoglycan in the periodontal ligament matrix (19). Antioedematous, anti-inflammatory and antibacterial effects of HA are also demonstrated in the treatment of periodontal diseases (20). $\mathrm{HA}$ is effective on the reduction of plaque index and sulcus bleeding index in gingivitis patients $(20,21)$. However, there are no differences in bacterial profile and clinical parameters when HA was applied subgingivally as adjunctive to scaling and root planning (SRP) in chronic periodontitis patients (22). On the other hand several clinical studies and reports have revealed additional clinical improvements in probing depth (PD) reduction and clinical attachment level (CAL) gain after the application of $\mathrm{HA}$ adjunctively to periodontal operation (23-25). A systematic review (26) concluded that the use of 
HA as an adjunct to both SRP in chronic periodontitis patients and surgical periodontal therapy provided positive effects on the bleeding on probing (BOP), PD, CAL and bone fill. In a recent systematic review and meta-analysis, it was stated that adjunctive use of HA may improve the clinical outcomes when used in conjunction with non-surgical and surgical periodontal therapy (27).

Smoking is one of the main risk factors for the initiation and progression of periodontal diseases. In addition to increasing periodontal destruction, previous data revealed that smoking also adversely affects the response to periodontal treatment (28-30).

To the best of the authors' knowledge, despite all aforementioned unique properties, there is no information about the effectiveness of HA as an adjunct to non-surgical periodontal treatment (NSPT) in smokers with periodontitis. Thus, the present retrospective study aimed to evaluate the clinical effectiveness of HA as adjunctive to NSPT in the management of periodontitis. The null hypothesis was that additional HA gel application during NSPT would not influence the outcomes in smokers.

\section{METHODS}

This retrospective clinical study was approved by Ethical Committee of Clinical Studies in the Marmara University with the reference number 2019-345.

\subsection{Study Population}

The data used in this study were extracted from the records of subjects who received NSPT from July 1, 2018 to January 1, 2019 at the Periodontology Clinics, Marmara University.

The inclusion criteria of the subjects were as follows: (a) systemically healthy, (b) periodontitis, (c) smoker ( $\geq 10$ cigarettes/day; $>5$ years), (d) aged between 18 and 65 years, (e) not existed any kind of periodontal surgery. Subjects with incomplete documentation and/or without at least 3-week follow-up observation were excluded.

A total of 4625 patients' data were screened and evaluated based on the inclusion criteria. Among them, 4605 patients' records were excluded from the study: 2778 patients had systemic disease and/or were non-smoker and/or presented presence of less than 16 teeth and/or gingivitis and/or history of antibiotic, anti-inflammatory; records of 256 patients were incomplete; 977 patients were not within the defined age range. Thus, our study proceeded with records of 20 patients who fulfilled the inclusion criteria. A written informed consent form was obtained from all subjects before NSPT.

Radiographic (Fig 1) and clinical data of 20 enrolled subjects were retrieved and the procedures and follow-up sessions were reviewed in their records, retrospectively. The patients included in study comply with the periodontitis stage III with regard to the extent and severity and grade $\mathrm{C}$ depending on the smoke (31). The same treatment protocol was applied to the clinical records of patients, who underwent either only NSPT or HA gel as adjunct to NSPT, as detailed below.

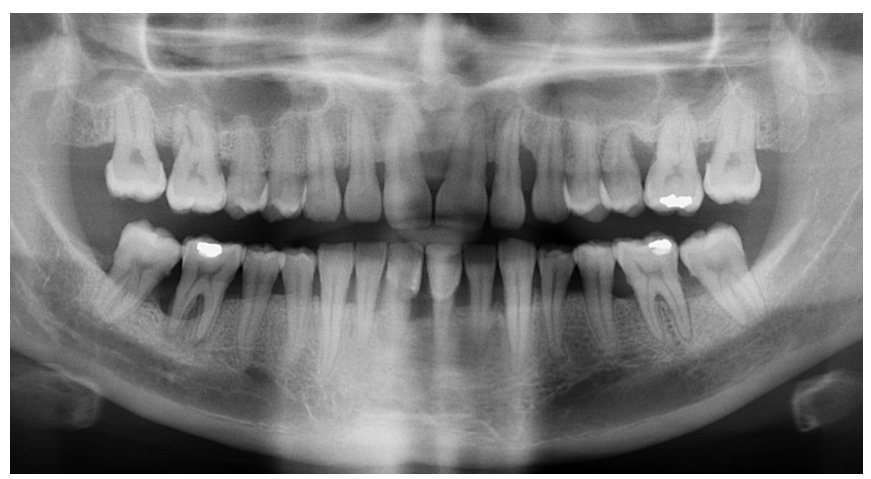

Figure 1. Radiographic view of one of the patient

\subsection{Treatment protocol}

Participants received oral hygiene instructions 1 week before the experimental period. At baseline, 1 and 3 months clinical parameters were recorded and GCF samples were collected. The GCF samples were collected from four distinct deeper pockets with standardized paper strips (PerioPaper, Proflow, Amityville, NY) which inserted at $1 \mathrm{~mm}$ depth at the entrance of the periodontal pocket, regardless of the PD, for 30 seconds following isolation of the sampling area. Strips visibly contaminated with microbial dental plaque, saliva or blood were excluded. A calibrated Periotron 8000 (OraFlow, Inc., Smithtown, NY, USA) was used to measure the GCF volume. SRP was performed with hand instruments (Gracey, SG 5/6, 7/8, 11/12, 13/14, Hu-Friedy Mfg. Co., LLC, Chicago, IL, USA) and an ultrasonic scaler (Cavitron ${ }^{\circ}$, BOBCAT $^{\circ}$ Pro, Dentsply International, USA) in two separate sessions with one week interval to both group. In the test group HA gel (Periosyal, Teoxane SA, Geneva, Switzerland) was applied to the gingival crevicular as an adjunct to NSPT in sessions. The gel inside the syringe was appled with a needle that allows it to reach the depth of the pocket until the pocket was filled with gel. Following this procedure, patients were asked not to eat or drink for one hour.

\subsection{Data extraction}

Clinical parameters in terms of plaque index (PI) (32), gingival index (GI) (33), BOP, PD, and CAL using the manual periodontal probe (UNC15; Hu-Friedy, Chicago, IL, USA) were considered at baseline, 1 and 3 months. The PI and GI were scored at 4 periodontal sites and the PD, CAL and BOP values were measured at 6 periodontal sites per tooth. The average scores for the whole-mouth PI, GI, BOP, PD and CAL; and GCF volume were calculated for each patient. The numerical readings of GCF volume were converted into actual volume $(\mu l)$ with the reference to formulation obtained from the standard curve. 


\subsection{Statistical analysis}

SPSS 20 (SPSS Corporation, Chicago, USA) was used for statistical analysis with a significance level of $5 \%$. The distribution for normality was checked via the KolmogorovSmirnov test. The Mann-Whitney $U$, the Kruskal-Wallis and Chi-Square tests were used to analyze intergroup differences. The Wilcoxon signed-rank and Friedman's test were performed to check repeated measurements of clinical parameters.

\section{RESULTS}

In Table 1, the demographic data of subjects without significant differences in gender and age $(p>0.05)$ is presented. No adverse effects were reported throughout the study period.
Tablo 1. Baseline data of patients

\begin{tabular}{|c|c|c|c|c|}
\hline Characteristic & $\begin{array}{l}\text { Total } \\
(\mathrm{N}=20)\end{array}$ & $\begin{array}{l}\text { Control Group } \\
\qquad(\mathrm{N}=10)\end{array}$ & $\begin{array}{l}\text { Test Group } \\
\qquad(\mathrm{N}=10)\end{array}$ & $p$ \\
\hline Gender (F/M) & $5 / 15$ & $2 / 8$ & $3 / 7$ & $0.606^{*}$ \\
\hline Age (Mean $\pm S D$ ) & 31.706 .23 & $31.10 \pm 6.02$ & $32.30 \pm 6.70$ & $0.739^{+}$ \\
\hline (Max-Min) & & $21-42$ & & \\
\hline
\end{tabular}

${ }^{*}$ Chi Square, ${ }^{\dagger}$ Mann-Whitney $U$ test, $p<0.05$

The periodontal clinical parameters in the control and test groups are shown in Table 2. At baseline, clinical parameters for all patients were similar for both groups $(p>0.05)$. The 1 and 3 months' evaluations yielded significant reductions compared with the baseline values in all periodontal parameters in both treatment groups $(p<0.05)$.

Table 2: Overview of all examined parameters

\begin{tabular}{|c|c|c|c|c|c|c|c|}
\hline & & \multicolumn{3}{|c|}{ Mean $\pm S D$} & \multicolumn{3}{|c|}{ Delta \pm SD } \\
\hline & Time Point & $\begin{array}{c}\text { Control Group } \\
(\mathrm{N}=10)\end{array}$ & $\begin{array}{l}\text { Test Group } \\
(\mathrm{N}=10)\end{array}$ & $\mathbf{p}^{*}$ & $\begin{array}{c}\text { Control Group } \\
(\mathrm{N}=10)\end{array}$ & $\begin{array}{l}\text { Test Group } \\
(\mathrm{N}=10)\end{array}$ & $p^{*}$ \\
\hline \multicolumn{8}{|l|}{ Clinical Parameters } \\
\hline \multirow[t]{3}{*}{ PI } & Baseline & $1.49 \pm 0.34$ & $1.48 \pm 0.64$ & 0.315 & & & \\
\hline & $1^{\text {st }}$ month & $0.43 \pm 0.21^{\mathrm{a}}$ & $0.26 \pm 0.35^{a}$ & 0.075 & $0.77 \pm 0.37$ & $1.00 \pm 0.30$ & 0.143 \\
\hline & $3^{\text {rd }}$ month & $0.32 \pm 0.14^{\mathrm{a}}$ & $0.19 \pm 0.17^{\mathrm{ab}}$ & 0.105 & $0.18 \pm 0.09$ & $0.15 \pm 0.14$ & 0.075 \\
\hline Intragroup $P$ value & & $0.000^{\ddagger}$ & $0.000^{\ddagger}$ & & & & \\
\hline \multirow[t]{3}{*}{ GI } & Baseline & $1.26 \pm 0.29$ & $1.52 \pm 0.46$ & 0.874 & & & \\
\hline & $1^{\text {st }}$ month & $0.49 \pm 0.28^{a}$ & $0.51 \pm 0.34^{\mathrm{a}}$ & 0.143 & $0.77 \pm 0.37$ & $1.00 \pm 0.30$ & 0.218 \\
\hline & $3^{\text {rd }}$ month & $0.32 \pm 0.22^{\mathrm{ac}}$ & $0.36 \pm 0.28^{\mathrm{ab}}$ & 0.971 & $0.18 \pm 0.09$ & $0.15 \pm 0.14$ & 0.247 \\
\hline Intragroup $P$ value & & $0.000^{\ddagger}$ & $0.000^{\ddagger}$ & & & & \\
\hline \multirow[t]{3}{*}{ BOP (\%) } & Baseline & $31.94 \pm 10.14$ & $39.61 \pm 10.02$ & 0.075 & & & \\
\hline & $1^{\text {st }}$ month & $4.27 \pm 1.26^{a}$ & $4.37 \pm 2.92^{\mathrm{a}}$ & 0.481 & $27.66 \pm 9.93$ & $35.24 \pm 10.71$ & 0.190 \\
\hline & $3^{\text {rd }}$ month & $3.41 \pm 0.70^{\mathrm{a}}$ & $3.23 \pm 2.45^{\mathrm{a}}$ & 0.529 & $0.86 \pm 1.53$ & $1.14 \pm 1.85$ & 0.529 \\
\hline Intragroup $P$ value & & $0.000^{\ddagger}$ & $0.000^{\ddagger}$ & & & & \\
\hline \multirow[t]{3}{*}{$\mathrm{PD}(\mathrm{mm})$} & Baseline & $2.92 \pm 0.60$ & $3.20 \pm 0.58$ & 0.315 & & & \\
\hline & $1^{\text {st }}$ month & $2.42 \pm 0.29^{a}$ & $2.35 \pm 0.56^{\mathrm{a}}$ & 1.000 & $0.49 \pm 0.48$ & $0.85 \pm 0.24$ & 0.089 \\
\hline & $3^{\text {rd }}$ month & $2.36 \pm 0.33^{d}$ & $2.30 \pm 0.72^{\mathrm{a}}$ & 0.853 & $0.06 \pm 0.14$ & $0.05 \pm 0.42$ & 0.529 \\
\hline Intragroup $P$ value & & $0.000^{\ddagger}$ & $0.001^{\ddagger}$ & & & & \\
\hline \multirow[t]{3}{*}{ CAL (mm) } & Baseline & $2.98 \pm 0.58$ & $3.35 \pm 0.54$ & 0.165 & & & \\
\hline & $1^{\text {st }}$ month & $2.48 \pm 0.28^{\mathrm{a}}$ & $2.79 \pm 0.89^{\mathrm{a}}$ & 0.436 & $0.55 \pm 0.49$ & $0.56 \pm 0.55$ & 0.912 \\
\hline & $3^{\text {rd }}$ month & $2.43 \pm 0.28^{d}$ & $2.75 \pm 0.78^{a}$ & 0.436 & $0.06 \pm 0.18$ & $0.04 \pm 0.15$ & 0.796 \\
\hline Intragroup $P$ value & & $0.002^{\ddagger}$ & $0.001^{\ddagger}$ & & & & \\
\hline \multicolumn{8}{|l|}{ GCF volume } \\
\hline \multirow[t]{3}{*}{ GCF $\left(\times 10^{5} \mathrm{CFU} / \mathrm{ml}\right)$} & Baseline & $0.42 \pm 0.12$ & $0.59 \pm 0.24$ & 0.105 & & & \\
\hline & $1^{\text {st }}$ month & $0.24 \pm 0.06^{\mathrm{a}}$ & $0.34 \pm 0.15^{\mathrm{e}}$ & 0.105 & $0.18 \pm 0.09$ & $0.18 \pm 0.09$ & 0.143 \\
\hline & $3^{\text {rd }}$ month & $0.14 \pm 0.07^{\mathrm{ac}}$ & $0.24 \pm 0.14^{\mathrm{fg}}$ & 0.143 & $0.25 \pm 0.26$ & $0.25 \pm 0.26$ & 0.853 \\
\hline Intragroup $P$ value & & $0.000^{\ddagger}$ & $0.002^{\ddagger}$ & & & & \\
\hline
\end{tabular}

${ }^{*}$ Mann-Whitney $U$ test, ${ }^{\dagger}$ Student- $t$ test, ${ }^{\ddagger}$ Friedman's two way test

PI: Plaque Index, GI: Gingival Index, BOP: Bleeding on Probing, PD: Probing Depth, CAL: CAL: Clinical Attachment Level, GCF: Gingival Crevicular Fluid ${ }^{a}$ Wilcoxon Signed Rank, $p=0.005$, compared to the baseline, ${ }^{b}$ Wilcoxon Signed Rank, $p=0.008$, compared to the 28th day, ${ }^{c}$ Wilcoxon Signed Rank, $p=0.005$, compared to the 28th day, ${ }^{d}$ Wilcoxon Signed Rank, $p=0.007$, compared to the baseline, ${ }^{e}$ Wilcoxon Signed Rank, $p=0.028$, compared to the baseline, ${ }^{f}$ Wilcoxon Signed Rank, $p=0.017$, compared to the baseline, ${ }^{g}$ Wilcoxon Signed Rank, $p=0.007$, compared to the 28th day 
No statistically significant inter-group differences were detected in any of the clinical parameters at any time points (all, $p>0.05$ ) and no significant differences in the changes $(\Delta)$ of clinical outcomes between baseline and 1 month (all, $p>0.05$ ) or changes between 1 and 3 months (all, $p>0.05$ ).

The mean values of GCF volume were similar in both groups at baseline and the treatments led a significant reduction in the GCF volumes $(\mu \mathrm{l})$ in both groups at 1 and 3 months $(p<0.05)$ (Table 1). Comparisons between baseline and followup measurements, and changes $(\Delta)$ revealed no significant differences in GCF volume between control and test groups at all evaluation time periods (Table 1 ).

\section{DISCUSSION}

The present study aimed to evaluate whether the use of HA gel may improve the outcomes obtained by NSPT in smoking patients periodontitis. NSPT is the most usual periodontal therapy that is effective in reducing $\mathrm{PD}, \mathrm{BOP}$ and improving CAL (34-36). Smoking patients with periodontitis are a therapeutically challenging subpopulation who may not respond to periodontal treatment as favorably as non-smoking patients (37-40). Generally, the outcomes have indicated that smoking promotes an unfavorable clinical response such as less PD reductions and lower clinical attachment gains after non-surgical and surgical periodontal treatments. As the smoking decreases the clinical effectiveness of SRP, some previous researches have suggested the use of therapeutic approaches such as local or systemic anti-inflammatory and antimicrobials agents as an adjunct to augment mechanical treatment to enhance the effects of initial periodontal treatment in smokers (4143). Considering the potential side effects of antibiotics together with limited benefits of short-term duration, in this study, the effect of HA application in addition to NSPT was evaluated. In a systematic review (26), it is concluded that most of clinical studies $(44,45)$ described a beneficial effect of HA with statistically significant reduction in BOP (2.28-19.5\%), PD (0.2-0.9 mm) and CAL gain comparing to controls; it was also reported that there were no side effects. Similarly, in a recently published meta-analysis (27) revealed that non-surgical treatment with adjunctive $\mathrm{HA}$ resulted in additional PD and BOP reduction (mean $-0.36 \mathrm{~mm}$ and $-15 \%$, respectively) and CAL gain (mean $0.73 \mathrm{~mm}$ ) compared with conventional SRP after 3 months. In the present study, NSPT with and without HA gel application resulted in an improvement in all clinical parameters. A similar positive change of all periodontal parameters in both groups shows that HA has no adjunctive clinical effect in smokers with periodontitis. The result of study is consistent with $\mathrm{Xu}$ et al. (22) who studied with chronic periodontitis population and did not find any difference in PD, BOP and CAL between test and control groups at 6 and 12 weeks follow-up after NSPT with or without HA gel. Engstrom et al. (46) also reported no difference in PD between the groups at 6 and 12 months after SRP. Furthermore, there is no study evaluating the use of HA in additional to NSPT in smokers, for that reason we cannot directly compare our results.

GCF, is a biological fluid used to assess the clinical status of periodontal tissues, is important for providing site-specific data. GCF also helps to evaluate periodontal tissue formation and destruction, disease activity and treatment effectiveness (47). In this study, the assessment of GCF samples throughout the study period aimed to support the clinical evaluation. The volume of GCF has been shown to be associated with the status of periodontal disease and is an indicator of gingival inflammation (48). A positive relationship between gingival inflammation and GCF volume has been reported $(47,48)$, as well as result of periodontal treatment, with reduced periodontal inflammation, a decrease in GCF volume is expected (49). Kanmaz et al. (50) reported similar volumes of GCF sample at baseline in the smoker and non-smoker patients with periodontitis stage III or IV, and grade C and significant reduction in the volumes of GCF following NSPT in both groups at 1-, 3-, and 6-months. Similarly, in this study it was found that both groups exhibited a significant and similar reduction in GCF volume throughout the 3-month study period.

Small sample size and the absence of a positive control group including placebo gel application may be the limitations of the present study. On the other hand, the outcomes obtained from this study will make important contributions to the limited information about the subject currently available in the literature.

\section{CONCLUSION}

Within the limits of the present study, it may be concluded that the additional HA gel application to NSPT of smoker patients with periodontitis may not demonstrate any further contribution to the rehabilitation.

\section{ACKNOWLEDGEMENTS}

The authors thank Prof. Dr. Leyla Kuru, Department of Periodontology, Faculty of Dentistry, Marmara University, Istanbul, Turkey, for the contributions.

\section{REFERENCES}

[1] Necas J, Bartosikova L, Brauner P, Kolar J. Hyaluronic acid (Hyaluronan): A review. Veterinarni Medicina 2008; 8: 397411.

[2] Embery G, Oliver WM, Stanbury JB, Purvis JA. The electrophoretic detection of acidic glycosaminoglycans in human gingival sulcus fluid. Arch Oral Biol 1982; 27(2): 177179.

[3] Fraser JR, Laurent TC, Laurent UB. Hyaluronan: its nature, distribution, functions and turnover. J Intern Med 1997; 242(1): 27-33.

[4] Pogrel MA, Lowe MA, Stern R. Hyaluronan (hyaluronic acid) in human saliva. Arc Oral Biol 1996; 41(7): 667-671. 
[5] Pirnazar P, Wolinsky L, Nachnani S, Haake S, Pilloni A, Bernard GW. Bacteriostatic Effects of Hyaluronic Acid. J Periodontol 1999; 70: 370-374.

[6] Laurent TC, Laurent UB, Fraser JR. Functions of hyaluronan. Ann Rheum Dis 1995; 54(5): 429-432.

[7] Kang JH, Kim YY, Chang JY, Kho HS. Influences of hyaluronic acid on the anticandidal activities of lysozyme and the peroxidase system. Oral Dis 2011; 17(6): 577-583.

[8] Sasaki T, Watanabe C. Stimulation of osteoinduction in bone wound healing by high-molecular hyaluronic acid. Bone 1995; 16(1): 9-15.

[9] Kawano M, Ariyoshi W, Iwanaga K, Okinaga T, Habu M, Yoshioka I, Tominaga K, Nishihara T. Mechanism involved in enhancement of osteoblast differentiation by hyaluronic acid. Biochem Biophys Res Commun 2011; 405(4): 575-580.

[10] Dahiya P, Kamal R. Hyaluronic Acid: a boon in periodontal therapy. N Am J Med Sci 2013; 5(5): 309-315.

[11] Deed R, Rooney P, Kumar P, Norton JD, Smith J, Freemont AJ, Kumar S. Early-response gene signalling is induced by angiogenic oligosaccharides of hyaluronan in endothelial cells. Inhibition by non-angiogenic, high-molecular-weight hyaluronan. Int J Cancer 1997; 71: 251-256.

[12] Ijuin C, Ohno S, Tanimoto K, Honda K, Tanne K. Regulation of hyaluronan synthase gene expression in human periodontal ligament cells by tumour necrosis factor-alpha, interleukin1 beta and interferon-gamma. Arch Oral Biol 2001; 46(8): 767772.

[13] Bartold PM, Wiebkin OW, Thonard JC. Glycosaminoglycans of human gingival epithelium and connective tissue. Connect Tissue Res 1981; 9(2): 99-106.

[14] Bartold PM, Page RC. Hyaluronic acid synthesized by fibroblasts cultured from normal and chronically inflamed human gingivae. Coll Relat Res 1986; 6(4): 365-377.

[15] Bartold PM. Proteoglycans of the periodontium: structure, role and function. J Periodontal Res 1987; 22(6): 431-444.

[16] Waddington RJ, Embery G, Last KS. Glycosaminoglycans of human alveolar bone. Arch Oral Biol 1989; 34(7): 587-589.

[17] Giannobile WV, Riviere GR, Gorski JP, Tira DE, Cobb CM. Glycosaminoglycans and periodontal disease: Analysis of GCF by safranin O. J Periodontol 1993; 64(3): 186-190.

[18] Shimabukuro Y, Ichikawa T, Takayama S, Yamada S, Takedachi M, Terakura M, Hashikawa T, Murakami S. Fibroblast growth factor-2 regulates the synthesis of hyaluronan by human periodontal ligament cells. J Cell Physiol 2005; 203(3): 557 563.

[19] Sukumar S, Drizhal I. Hyaluronic acid and periodontitis. Acta Medica (Hradec Kralove) 2007; 50(4): 225-228.

[20] Jentsch H, Pomowski R, Kundt G, Göcke R. Treatment of gingivitis with hyaluronan. J Clin Periodontol 2003; 30(2): 159164.

[21] Pistorius A, Martin M, Willershausen B, Rockmann P. The clinical application of hyaluronic acid in gingivitis therapy. Quintessence Int 2005; 36(7-8): 531-538.

[22] Xu Y, Höfling K, Fimmers R, Frentzen M, Jervøe-Storm PM. Clinical and microbiological effects of topical subgingival application of hyaluronic acid gel adjunctive to scaling and root planing in the treatment of chronic periodontitis. J Periodontol 2004; 75(8): 1114-1118.

[23] Briguglio F, Briguglio E, Briguglio R, Cafiero C, Isola G. Treatment of infrabony periodontal defects using a resorbable biopolymer of hyaluronic acid: a randomized clinical trial. Quintessence Int 2013; 44(3): 231-240.

[24] Fawzy El-Sayed KM, Dahaba MA, Aboul-Ela S, Darhous MS. Local application of hyaluronan gel in conjunction with periodontal surgery: a randomized controlled trial. Clin Oral Investig 2012; 16(4): 1229-1236.

[25] Vanden Bogaerde L. Treatment of infrabony periodontal defects with esterified hyaluronic acid: clinical report of 19 consecutive lesions. Int J Periodontics Restorative Dent 2009; 29(3): 315-323.

[26] Bertl K, Bruckmann C, Isberg PE, Klinge B, Gotfredsen $K$, Stavropoulos A. Hyaluronan in non-surgical and surgical periodontal therapy: a systematic review. J Clin Periodontol 2015; 42(3): 236-246.

[27] Eliezer M, Imber JC, Sculean A, Pandis N, Teich S. Hyaluronic acid as adjunctive to non-surgical and surgical periodontal therapy: a systematic review and meta-analysis. Clin Oral Investig 2019; 23(9): 3423-3435.

[28] Heasman L, Stacey F, Preshaw PM, McCracken GI, Hepburn $\mathrm{S}$, Heasman PA. The effect of smoking on periodontal treatment response: a review of clinical evidence. J Clin Periodontol 2006; 33(4): 241-253.

[29] Labriola A, Needleman I, Moles DR. Systematic review of the effect of smoking on nonsurgical periodontal therapy. Periodontol 2000 2005; 37: 124-137.

[30] Mullally BH, Breen B, Linden GJ. Smoking and patterns of bone loss in early-onset periodontitis. J Periodontol 1999; 70(4): 394-401.

[31] Papapanou PN, Sanz M, Buduneli N, Dietrich T, Feres M, Fine DH, Flemmig TF, Garcia R, Giannobile WV, Graziani F, Greenwell $H$, Herrera D, Kao RT, Kebschull M, Kinane DF, Kirkwood KL, Kocher T, Kornman KS, Kumar PS, Loos BG, Machtei E, Meng H, Mombelli A, Needleman I, Offenbacher S, Seymour GJ, Teles R, Tonetti MS. Periodontitis: Consensus report of workgroup 2 of the 2017 World Workshop on the Classification of Periodontal and Peri-Implant Diseases and Conditions. J Periodontol. 2018; 89:173-182.

[32] Silness J, Loe H. Periodontal Disease in Pregnancy. II. Correlation between Oral Hygiene and Periodontal Condtion. Acta Odontol Scand 1964; 22: 121-135.

[33] Loe H, Silness J. Periodontal Disease in Pregnancy. I. Prevalence and Severity. Acta Odontol Scand 1963; 21: 533-551.

[34] Badersten A, Nilveus R, Egelberg J. Effect of nonsurgical periodontal therapy. I. Moderately advanced periodontitis. J Clin Periodontol 1981; 8(1): 57-72.

[35] Badersten A, Nilveus R, Egelberg J. Effect of nonsurgical periodontal therapy. II. Severely advanced periodontitis. J Clin Periodontol 1984; 11(1): 63-76.

[36] Loos B, Nylund K, Claffey N, Egelberg J. Clinical effects of root debridement in molar and non-molar teeth. A 2-year follow-up. J Clin Periodontol 1989; 16(8): 498-504.

[37] Ah MK, Johnson GK, Kaldahl WB, Patil KD, Kalkwarf KL. The effect of smoking on the response to periodontal therapy. J Clin Periodontol 1994; 21(2): 91-97.

[38] Kaldahl WB, Johnson GK, Patil KD, Kalkwarf KL. Levels of cigarette consumption and response to periodontal therapy. J Periodontol 1996; 67(7): 675-681.

[39] Kinane DF, RadvarM. The effect of smoking on mechanical and antimicrobial periodontal therapy. J Periodontol 1997; 68(5): 467-472. 
[40] Trombelli L, Cho KS, Kim CK, Scapoli C, Scabbia A. Impaired healing response of periodontal furcation defects following flap debridement surgery in smokers. A controlled clinical trial. J Clin Periodontol 2003; 30(1): 81-87.

[41] Machion L, Andia DC, Benatti BB, Carvalho MD, NogueiraFilho GR, Casati MZ, Nociti FH Jr, Sallum EA. Locally delivered doxycycline as an adjunctive therapy to scaling and root planing in the treatment of smokers: a clinical study. J Periodontol 2004; 75(3): 464-469.

[42] Machion L, Andia DC, Lecio G, Nociti FH Jr, Casati MZ, Sallum AW, Sallum EA. Locally delivered doxycycline as an adjunctive therapy to scaling and root planing in the treatment of smokers: a 2-year follow-up. J Periodontol 2006; 77(4): 606613.

[43] Machion L, Andia DC, Saito D, Klein MI, Gonçalves RB, Casati MZ, Nociti FH Jr, Sallum EA. Microbiological changes with the use of locally delivered doxycycline in the periodontal treatment of smokers. J Periodontol 2004; 75(12): 1600-1604.

[44] Eick S, Renatus A, Heinicke M, Pfister W, Stratul SI, Jentsch H. Hyaluronic Acid as an adjunct after scaling and root planing: a prospective randomized clinical trial. J Periodontol 2013; 84(7): 941-949.

[45] Johannsen A, Tellefsen M, Wikesjö U, Johannsen G. Local delivery of hyaluronan as an adjunct to scaling and root planing in the treatment of chronic periodontitis. J Periodontol 2009; 80(9): 1493-1497.

[46] Engstrom PE, Shi XQ, Tronje G, Larsson A, Welander U, Frithiof $L$, Engstrom GN. The effect of hyaluronan on bone and soft tissue and immune response in wound healing. J Periodontol 2001; 72(9): 1192-1200.

[47] Griffiths GS. Formation, collection and significance of gingival crevice fluid. Periodontol 2000 2003; 31: 32-42.

[48] Goodson JM. Gingival crevice fluid flow. Periodontol 2000 2003; 31: 43-54.

[49] Gomes SC, Piccinin FB, Oppermann RV, Susin C, Marcantonio RA. The effect of smoking on gingival crevicular fluid volume during the treatment of gingivitis. Acta Odontol Latinoam 2009; 22(3): 201-206.

[50] Kanmaz B, Lappin DF, Nile CJ, Buduneli N. Effects of smoking on non-surgical periodontal therapy in patients with periodontitis stage III or IV, and grade C. J Periodontol 2019; 91(4):442-453.

How to cite this article: Ozturk Ozener H, Agrali OB, Yildirim HS. Efficacy of Hyaluronic Acid Gel as an Adjunct to Non-Surgical Periodontal Treatment in Smokers with Periodontitis: A Retrospective Case Control Study. Clin Exp Health Sci 2020; 10: 172-177. DOI: 10.33808/clinexphealthsci.709327 